\title{
The olfactive responses of Tetranychus urticae natural enemies in citrus depend on plant genotype, prey presence, and their diet specialization
}

Cabedo-López, Marc ${ }^{1}$, Cruz-Miralles, Joaquín ${ }^{1}$, Vacas, Sandra ${ }^{2}$, Navarro-Llopis, Vicente $^{2}$, Pérez-Hedo, Meritxell ${ }^{1,3}$, Flors, Víctor ${ }^{4}$ and Jaques, Josep A. ${ }^{*}$

1 Unitat Associada d'Entomologia Agrícola UJI-IVIA, Departament de Ciències Agràries i del Medi Natural, Universitat Jaume I (UJI), Castelló de la Plana, Spain.

2 Centro de Ecología Química Agrícola - Instituto Agroforestal del Mediterráneo. Universitat Politècnica de València, València, Spain

3 Unitat Associada d'Entomologia Agrícola UJI-IVIA, Institut Valencià d'Investigacions Agràries (IVIA), Centre de Protecció Vegetal i Biotecnologia, Montcada, Spain.

4 Integración Metabólica y Señalización Celular, Departament de Ciències Agràries i del Medi Natural, Universitat Jaume I (UJI), Castelló de la Plana, Spain.

*Correspondence:

Prof. Josep Anton Jaques Miret

josep.jaques@camn.uji.es +34 964728038

MCL and JCM should be considered joint first author. 


\begin{abstract}
Sour orange, Citrus aurantium, displays higher constitutive and earlier inducible direct defenses against the two-spotted spider mite, Tetranychus urticae, than Cleopatra mandarin, Citrus reshni. Moreover, herbivore induced plant volatiles (HIPVs) produced by sour orange upon infestation can induce resistance in Cleopatra mandarin but not viceversa. Because the role of these HIPVs in indirect resistance remains ignored, we have carried out a series of behavioral assays with three predatory mites with different levels of specialization on this herbivore, from strict entomophagy to omnivory. We have further characterized the volatile blend associated with $T$. urticae, which interestingly includes the HIPV methyl salycilate, as well as that produced by induced Cleopatra mandarin plants. Although a preference for less defended plants with presumably higher prey densities (i.e., C. reshni) was expected, this was not always the case. Because predators' responses changed with diet width, with omnivore predators responding to both HIPVs and prey-related odors and specialized ones mostly to prey, our results reveal that these responses depend on plant genotype, prey presence, and predator diet specialization. As the different volatile blends produced by infested sour orange, induced Cleopatra mandarin and T. urticae itself are attractive to T. urticae natural enemies but not to the herbivore, they may provide clues to develop new more sustainable tools to manipulate these agriculturally relevant species.
\end{abstract}

Key words: sour orange; Cleopatra mandarin; Phytoseiulus persimilis; Neoseiulus californicus; Euseius stipulatus; HIPV. 


\section{Key message:}

- The role of herbivore induced plant volatiles (HIPVs) produced by citrus upon infestation by T. urticae in indirect resistance remains ignored.

- A higher attraction of phytoseiids for plants exhibiting relatively lower direct defense was expected.

- Omnivorous predators responded to both HIPVs and prey-related odors whereas specialized ones responded mostly to prey.

- Volatile blends attractive to T. urticae natural enemies but not to the herbivore may offer new opportunities to manage this system in a more sustainable way. 


\section{INTRODUCTION}

Spider mites (Acari: Tetranychidae) comprise more than one thousand plant-feeding species worldwide (Migeon and Dorkeld 2006-2017). One of these species is the twospotted spider mite, Tetranychus urticae Koch, a highly polyphagous and cosmopolitan species (Migeon and Dorkeld 2006-2017). The pest status of this herbivore changed from minor to key pest of many food and ornamental crops after World War II (Hoy 2011; Pérez-Sayas et al. 2015). The disruption of existing top-down regulation mechanisms (i.e., natural enemies) by pesticide abuse during the second half of the XX century is recognized as one of the main causes for that change (Huffaker et al. 1970). More recently, the implication of bottom-up regulation mechanisms by replacement of traditional resistant crops by more susceptible genotypes has been also highlighted (Bruessow et al. 2010; Agut et al. 2014). These studies focused on citrus, one of the many crops where T. urticae is considered a pest (Jacas and Urbaneja 2010). Indeed, in the case of clementine mandarins (Citrus clementina Hort. ex Tan.), T. urticae can achieve the status of key pest (Pascual-Ruiz et al. 2014; Gómez-Martínez et al. 2018).

Commercial citrus plants are regularly propagated vegetatively by bud-grafting onto a seedling rootstock. Sour orange, Citrus aurantium L. (Sapindales: Rutaceae), was the most widespread rootstock until the 1950s, when the emergence of the citrus quick decline disease caused by the Citrus Tristeza Virus (CTV, Closteroviridae) proved lethal for this rootstock. This triggered its massive replacement around the world (Cambra et al. 2000). Sour orange, though, is highly resistant to T. urticae, while one of the alternative CTV-tolerant rootstocks, Cleopatra mandarin, Citrus reshni Hort. ex Tan., is highly susceptible to this mite (Bruessow et al. 2010). Agut et al. (2016) provided evidence that resistance in sour orange was systemically transmitted from the roots to the shoots of the grafted cultivar. Both the jasmonic acid (JA) and the salicylic acid (SA) pathways were upregulated in sour orange plants upon mite attack, while these pathways remained unchanged in infested Cleopatra mandarin. However, the SA pathway proved irrelevant for the enhanced direct defense of sour orange (Agut et al. 2014). Further studies (Agut et al. 2015) showed that the release of T. urticae HIPVs (herbivore induced plant volatiles) from sour orange [namely, the terpenes $\alpha$-ocimene, $\alpha$-farnesene, pinene and Dlimonene, and the green leaf volatile (GLV) 4-hydroxy-4-methyl-2-pentanone] had a marked repellent effect on conspecific mites and induced resistance in Cleopatra mandarin plants. Oviposition rates decreased while both the JA and the SA pathways were stimulated in this rootstock. Contrarily, Cleopatra mandarin HIPVs [namely, (2- 
butoxyethoxy) ethanol, benzaldehyde, and methyl salicylate, MeSA] had a marked attractant effect on conspecific mites and did not induce any resistant response in uninfested Cleopatra mandarins. However, the potential role of these induced volatiles in indirect defense, i.e., the attraction of the natural enemies of the herbivore (Aljbory and Chen 2018; Cortés et al. 2016), remains unknown. Therefore, this system offers a good opportunity to study the possible effect of plant genotype on the behavior of $T$. urticae natural enemies. Because for a predator, directing its food search toward HIPVs emitted by well-defended plants may reduce its fitness, as its chances of finding abundant and well-nourished prey are lower, we would expect a higher attraction of clean Cleopatra mandarin relative to induced Cleopatra plants and clean sour orange.

The main natural enemies of T. urticae are predatory mites of the family Phytoseiidae (Acari: Mesostigmata). Euseius stipulatus (Athias-Henriot), Neoseiulus californicus (McGregor) and Phytoseiulus persimilis (Athias-Henriot) are the most common phytoseiids naturally associated with T. urticae in the canopy of Spanish citrus orchards (Abad-Moyano et al. 2009; Aguilar-Fenollosa et al. 2011). These predators have different diet specializations, ranging from selective predators of Tetranychus spp., as $P$. persimilis, to extreme diet generalists, omnivores feeding on both animal and plant derived food, as E. stipulatus, for which plant cell-sap feeding is suspected (Adar et al. 2012). The Tetranychidae specialist $N$. californicus would occupy an intermediate position feeding on both prey and plant derived food (i.e., pollen) (McMurtry and Croft 1997; McMurtry et al. 2013). However, same as P. persimilis, N. californicus is not considered a plant cell-sap feeding phytoseiid (Adar et al. 2012). These diet specializations may also have consequences on the behavior of predators and affect their choices. Although, as pointed out earlier, predators would benefit from choosing less defended plants, plant cell-sap-feeding, which would allow this type of omnivorous predators to switch to plant feeding when prey is scarce could result in a stronger attraction for these plants, which could be missing in strict entomophagous predators (i.e., P. persimilis).

Here, we present a study of the effects of plant genotype and predator diet specialization on the indirect plant defense responses triggered by T. urticae in citrus. To achieve this goal, we have carried out a series of Y-tube olfactory choice assays (Bruin et al. 1992) using the two extreme citrus genotypes partly characterized in terms of their response to T. urticae herbivory (defensive pathways and HIPV profiles): sour orange and Cleopatra 
mandarin (Agut et al. 2014, 2015, 2016). We have also characterized the volatile blends produced by induced Cleopatra mandarin and T. urticae.

\section{MATERIALS AND METHODS}

\section{Plant material}

Sour orange, Cleopatra mandarin, clementine mandarin (C. clementina cv. Clementina de Nules grafted on citrange Carrizo rootstock) and bean (Phaseolus vulgaris L. cv. Buenos Aires roja) plants were used in our assays. These plants were grown on vermiculite and peat $(1: 3 ; \mathrm{v}: \mathrm{v})$. No pesticides were applied to these plants, which were watered every 3 days with approximately $30 \mathrm{ml}$ of a 1:100 (vol:vol) modified Hoagland's solution (Bañuls et al. 1997). Bean plants were used for rearing purposes only (see below).

Three-month-old plants of sour orange and Cleopatra mandarin were used in the behavioral assays (see below). They were maintained in a climatic chamber at $22 \pm 2.5^{\circ} \mathrm{C}$ and $60 \pm 10 \%$ relative humidity $(\mathrm{RH})$ under a 16:8 h L:D (Light:Dark) photoperiod. Twoyear-old clementine mandarin plants maintained in a greenhouse at $25 \pm 10^{\circ} \mathrm{C}, 75 \pm 30 \%$ RH, under natural photoperiod and lemon (Citrus limon (L.) Burm f.) fruit obtained from a pesticide-free orchard at Universitat Jaume I Riu Sec Campus (UJI; 3059'38'’N; $0^{\circ} 03^{\prime} 59^{\prime}$ ' $\mathrm{W}, 30 \mathrm{~m}$ alt.), the same location, were used to maintain $T$. urticae stock colonies. Finally, pesticide-free bean leaves obtained from plants grown at UJI greenhouses were used to maintain E. stipulatus and P. persimilis colonies.

\section{Spider mite stock colony}

The colony of $T$. urticae used in the assays was initiated with specimens collected in clementine mandarin orchards in the region of La Plana (Castelló, Spain) in 2011. Mites were maintained on lemons kept in a climatic chamber $\left(22 \pm 2.5^{\circ} \mathrm{C}\right.$ and $75 \pm 5 \% \mathrm{RH}$ and 16:8 h L:D photoperiod). Colonies consisted of 8-10 lemons, which were replaced weekly in groups of four. Adult females (5-6 day-old) obtained from these stock colonies were used in the behavioral assays (see below), either directly to infest citrus plants, or subjected to a previous 24-h starvation period, before measuring their preferences. For the characterization of $T$. urticae associated volatiles, we used individuals from these colonies but also from an additional colony maintained on detached clementine mandarin leaves. These leaves were placed upside down on top of sponges $(14 \times 14 \times 4 \mathrm{~cm})$ covered 
with cotton in water-containing trays $(35 \times 20 \times 7 \mathrm{~cm})$ that served both as a water source for leaves and mites and as a barrier against mite dispersal.

\section{Phytoseiidae mite stock colony}

Three different phytoseiid mite species were used in our studies: E. stipulatus, $N$. californicus and $P$. persimilis. Colonies of $P$. persimilis and E. stipulatus were initiated with specimens collected in clementine mandarin orchards in the region of La Plana (Castelló, Spain) whereas N. californicus was obtained from Koppert Biological Systems (SPICAL $\left.{ }^{\circledR}\right)$ and these specimens were directly used in our choice tests. The colonies of $P$. persimilis and E. stipulatus were maintained on detached leaves of bean plants in a climatic chamber at the same conditions as above. The rearing took place on units consisting of a single bean leaf placed upside down on moistened cotton, placed on top of a water-saturated sponge in water-containing trays as before. Moist cotton was folded over the edges of the leaves to prevent mites from escaping. A mix of different stages of T. urticae was provided twice a week to P. persimilis, whereas E. stipulatus was supplied Typha L. spp. (Typhaceae) pollen, only. 5-6 day-old phytoseiid adult females obtained from these stock colonies were used in the behavioral assays (see below).

\section{Y-tube olfactory choice assays}

Olfactory choice assays were conducted using a Y-tube olfactometer according to Bruin et al. (1992). This assay involves the use of a 4-cm-diameter Y-shaped glass tube with a $13 \mathrm{~cm}$ base and two $13 \mathrm{~cm}$ arms containing a Y-shaped 1-mm diameter metal wire of the same dimensions, which occupies the core of the olfactometer. The two short arms were directly connected via a plastic pipeline to the outlets of two identical 5-1 glass vessels (Duran, Mainz, Germany) containing different odor sources (mite odors, plant odors or a combination of both, see Figure 1-4). Each vessel was connected to an air pump that produced a unidirectional airflow of $1.51 \mathrm{~h}^{-1}$ (measured with a flowmeter) from the arms to the base of the tube. The air was purified with a granular activated charcoal filter (Sigma-Aldrich). The environmental conditions inside the Y-tube were $23 \pm 2{ }^{\circ} \mathrm{C}$ and 60 $\pm 10 \% \mathrm{RH}$. Adult females offered water only during the $24 \mathrm{~h}$ before the assay, were individually deposited at the beginning of the basal arm of the wire using a soft-bristle paintbrush. Females were allowed to make a choice within $10 \mathrm{~min}$. As soon as a mite reached the end of one of the two arms of the Y-tube, the mite was removed from the setup and discarded. Mites failing to reach either end of the two arms within the allocated time were scored as 'no choice'. Each combination was evaluated four times at different 
dates (i.e., four replicates). Each replicate included 10 responding mites which meant that up to 13 mites per combination per date were tested as the non-choice rate ranged from 0 to 3 . The glass vessels were switched after five females had been tested. After every 10 females had been tested, the plants were replaced and the whole system was rinsed with ethanol (70\%), followed by air drying. The glass vessels were switched to reduce the effects of spatial influence on choice. To exclude any bias from the set-up, before the beginning of the assays, 10 mites were exposed to clean air in both arms.

\section{Effect of HIPVs on neighboring plants}

To determine the effect of the volatiles released by Cleopatra mandarin plants previously exposed to T. urticae-infested sour orange on mite behavior, an olfactory choice assay was performed. First, sour orange plants were infested with 25 adult $T$. urticae females per plant. After $24 \mathrm{~h}$, one infested sour orange plant was placed in a tray $(65 \times 50 \times 30$ $\mathrm{cm}$ ) containing five untreated Cleopatra mandarin plants. Subsequently, the tray was covered with a transparent lid. To avoid mite ambulatory dispersal, the tray was filled with water. After $72 \mathrm{~h}$, one Cleopatra mandarin and one sour orange plants were defoliated. Detached leaves were immediately frozen at $-80^{\circ} \mathrm{C}$ for further analysis (mRNA expression). The remaining four presumably-induced Cleopatra mandarin plants were used in an olfactory choice assay together with control plants where the preferences of T. urticae, E. stipulatus, $N$. californicus and P. persimilis were studied following the same procedure as above.

\section{Quantitative real-time reverse transcription-polymerase chain reaction (qRT-PCR) analysis}

RNA was extracted using a plant RNA protocol with trizol (Kiefer et al. 2000). For qRTPCR experiments, $1 \mu \mathrm{g}$ of total RNA was digested with $0.7 \mu \mathrm{g}$ of DNase (RNase-free DNase I) in $0.7 \mu 1$ of DNase buffer and Milli-Q water up to $4.9 \mu 1$ and incubated for 30 min at $37^{\circ} \mathrm{C}$. After incubation, $0.7 \mu \mathrm{l}$ of EDTA was added and incubated again at $65^{\circ} \mathrm{C}$ for $10 \mathrm{~min}$ to inactivate DNase (Thermofisher Scientific Inc.). The RT reaction was performed by adding $7 \mu 1$ of DNase reaction, $2 \mu 1$ of PrimeScript buffer and $0.5 \mu 1$ of PrimeScript RT and Oligo-dT respectively (PrimeScript RT Reagent Kit, Takara Bio Inc.). The reaction mixture was incubated at $37^{\circ} \mathrm{C}$ for $15 \mathrm{~min}$. Complementary DNA from the RT reaction, 10X diluted, was used for qPCR. Forward and reverse primers $(0.3 \mu \mathrm{M})$ were added to $5 \mu 1$ of Maxima SYBR Green qPCR Master Mix, $1 \mu 1$ of cDNA and $3 \mu 1$ Milli-Q sterile water (Maxima SYBR Green/ROX qPCR, Thermofisher Scientific Inc.). 
qPCR was carried out using the Smart Cycler II (Cepheid, Sunnyvale, CA, USA) sequence detector with standard PCR conditions $\left(95^{\circ} \mathrm{C}-10 \mathrm{~min} ; 40 \times\left(95^{\circ} \mathrm{C}-10 \mathrm{sec} ; 55^{\circ} \mathrm{C}\right.\right.$ $\left.\left.10 \mathrm{sec} ; 72^{\circ} \mathrm{C}-20 \mathrm{sec}\right) ; 60^{\circ} \mathrm{C}-10 \mathrm{sec} ; 95^{\circ} \mathrm{C}-15 \mathrm{sec}\right)$. qRT-PCR analysis was replicated three times. The primer of lipoxygenase 2 ( $L O X 2)$ and pathogenesis-related protein 5 (PR5) was determined. Relative expression was compared with the housekeeping gene glyceraldehyde 3-phosphate dehydrogenase (GAPDH) (Table 1 Suppl.).

\section{Characterization of Cleopatra-mandarin volatiles induced by exposure to sour orange HIPVs}

Volatiles emitted by Cleopatra mandarin plants previously exposed to T. urticae-infested sour orange (see above) and Cleopatra mandarin control plants were collected using a headspace collection system similar to that described by Bruinsma et al. (2010). Open glass vials containing $300 \mathrm{mg}$ of Porapak (Sigma-Aldrich, Barcelona, Spain) were used as volatile retention filters. They were connected to the air outlet hole at the top of 5-1 glass vessels described above. This system was ventilated with carbon-filtered pressureair at $1.5 \mathrm{l} / \mathrm{h}$. The system (glass vessels and Porapak filters) was cleaned with acetone and dried in an oven 1 hour prior to the assay. Plants were set individually inside these glass vessels. Volatile compounds were collected in $1 \mathrm{ml}$ of ethyl acetate. This collection took place in a climatic chamber at $22 \pm 2.5^{\circ} \mathrm{C}$ and $60 \pm 10 \%$ relative humidity $(\mathrm{RH})$ under a 16:8 h L:D photoperiod during 24 hours. An Agilent 6890N GC system (Palo-Alto, CA, USA), equipped with an Agilent 7683 autosampler, coupled to a time-of-flight mass spectrometer (TOF-MS), GCT (Waters Corp., Manchester, UK), operating in electron ionization (EI) mode was used to characterize the volatiles. A fused silica DB-5MS capillary column of $30 \mathrm{~m}$ length, $0.25 \mathrm{~mm}$ internal diameter and a film thickness of 0.25 $\mu \mathrm{m}$ (J\&W Scientific, Folson, CA, USA) was used to the GC separation. The temperature program for this process was the following; $50^{\circ} \mathrm{C}(1 \mathrm{~min}) ; 5^{\circ} \mathrm{C} \min ^{-1}$ to $210^{\circ} \mathrm{C}(1 \mathrm{~min})$;

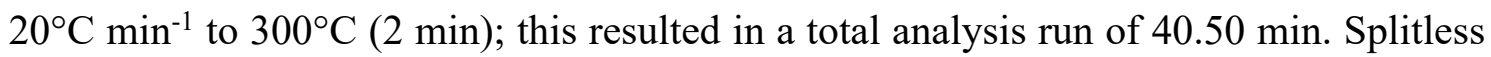
injections were carried out. Helium was used as carrier gas at $1 \mathrm{ml} \mathrm{min}^{-1}$. The interface and source temperatures were both set to $250^{\circ} \mathrm{C}$ and a solvent delay of 3 min was selected. The TOF-MS was operated at 1 spectrum $\mathrm{s}^{-1}$ acquiring the mass range $\mathrm{m} / \mathrm{z}$ 50-650 and using a multi-channel plate voltage of $2800 \mathrm{~V}$. The TOF-MS resolution was c. 8500 (full width at half-maximum, FWHM) at $\mathrm{m} / \mathrm{z}$ 614. Heptacose, used for the daily mass calibration as well as lock mass, was injected via syringe into the reference reservoir at $30^{\circ} \mathrm{C}$. The $\mathrm{m} / \mathrm{z}$ ion monitored was 218.9856 . The application manager ChromaLynx, a module of MassLynx software, was used to investigate the presence of non-target 
compounds in the samples. Volatiles were identified by matching to the National Institute of Standards and Technology library (NIST $\backslash E P A \backslash N I H$ Mass Spectral Library, version 2.0, build $4 / 2005$ ) using match values of at least $>80 \%$ as a threshold for identification, as described by Wallis et al. (2008). Finally, for each volatile identified the TOF-MSderived peak areas were calculated.

\section{Characterization of Tetranychus urticae associated volatiles}

Groups of 1000-2000 spider mite individuals (mixed instars and sexes) were placed in 20-ml closed screw-cap headspace vials by carefully brushing the rearing substrate. Volatiles were collected in static conditions by solid-phase microextraction (SPME) using Supelco SPME holders equipped with a polydimethylsiloxane/divinylbenzene fiber (PDMS/ DVB), film thickness $=100 \mu \mathrm{m}$ (Supelco Inc., Bellefonte, PA, USA). SPME fibers were conditioned before volatile sampling in a $\mathrm{GC}$ injector at $250^{\circ} \mathrm{C}$ for $10 \mathrm{~min}$

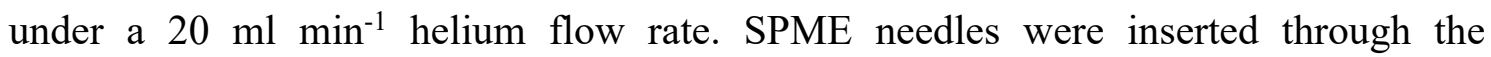
polytetrafluoroethylene (PTFE)-silicone septa, and fibers were exposed to each sample for $24 \mathrm{~h}$ at $23 \pm 2^{\circ} \mathrm{C}$, under a 16:8 h L:D photoperiod. This sampling period was chosen in order to achieve maximum sensitivity (Alfaro et al. 2011). Then, fibers were removed and inserted into the GC injection port to desorb volatiles. Nine replicates were carried out with different groups of T. urticae individuals, six of them obtained from the colony maintained on lemons, and three from the colony on clementine mandarin leaves. SPME fibers were thermally desorbed into the GC injection port, set at $250^{\circ} \mathrm{C}$ for $1 \mathrm{~min}$, and operated in the splitless mode. The extracted volatiles were analyzed by GC-MS using a Clarus 600 GC-MS (PerkinElmer Inc., Wellesley, MA, USA). The column used was a 30 $\mathrm{m} \times 0.25 \mathrm{~mm}$ i.d., $0.25 \mu \mathrm{m}$ film thickness, ZB-5MS fused silica capillary column (Phenomenex Inc., Torrance, CA, USA). The oven was held at $40^{\circ} \mathrm{C}$ for $2 \mathrm{~min}$ and then programmed at $5^{\circ} \mathrm{C} \min ^{-1}$ to $180^{\circ} \mathrm{C}$; when reached, temperature was raised to $280^{\circ} \mathrm{C}$ at $10^{\circ} \mathrm{C} \mathrm{min}^{-1}$ and maintained at $280^{\circ} \mathrm{C}$ for $1 \mathrm{~min}$ (total analysis run of $41 \mathrm{~min}$ ). Helium was used as the carrier gas with a flow rate of $1.2 \mathrm{ml} \mathrm{min}^{-1}$. Detection was performed in the EI mode (ionization energy, $70 \mathrm{eV}$; source temperature, $180^{\circ} \mathrm{C}$ ), and spectra acquisition was done in the scanning mode (mass range $\mathrm{m} / \mathrm{z} 35-400$ ). Chromatograms and spectra were recorded with GC-MS Turbomass software version 5.4 (PerkinElmer Inc.). Volatiles were identified by either comparing their retention times and mass spectra with those of pure standards (Sigma-Aldrich) or, same as before, by matching to the National Institute of Standards and Technology library (NIST $\backslash E P A \backslash N I H$ Mass Spectral Library, version 2.0 , build $4 / 2005$ ) using match values of at least $>80 \%$ as a threshold for 
identification, as described by Wallis et al. (2008). For each rearing substrate, the different peak areas in the chromatogram corresponding to these compounds were calculated and used to estimate their relative abundance in the blend.

\section{Statistical analysis}

Statistical analyses were conducted using IBM SPSS Statistics 23. The results of the twochoice assays were initially subjected to logistic regression to check for the effect of replicate $(n=4)$ on mite preference. Depending on whether this effect was significant or not $(P>0.05)$, either each single replicate or the combination of the four, respectively, were subjected to chi-square analysis to test whether they departed from a 1:1 distribution. Student $t$-tests were used to compare the results of genetic expression results. The TOFMS-derived peak areas were checked for normality (Shapiro-Wilk test) and homogeneity of variance (Levene's test). As these assumptions were fulfilled, the area values were subjected to analysis of variance (ANOVA; $P<0.05$ ).

\section{RESULTS}

In order to understand the role of HIPVs in direct and indirect defense we first confirmed that sour orange strongly reacts to T. urticae infestation by triggering expression of both LOX2 and PR5 marker genes of the JA and the SA-signaling pathways, respectively (Figures 1A and 2A Suppl.). Likewise, Cleopatra mandarin could be stimulated by sour orange HIPVs that triggered an upregulation of $L O X 2$ and $P R 5$ gene expression (Figures 1B and 2B Suppl.).

Preferences of adult $T$. urticae females when exposed to the odors of clean and infested plants, which had already been recorded in our previous work (Agut et al. 2015), were studied again. In addition, we also checked the responses to conspecific mites alone, and to induced Cleopatra mandarin. As the effect of the factor 'replicate' was not significant in any case, for each 2-choice experiment, the results of the four replicates were pooled and subjected to chi-square test. Preferences are shown in Figure 1. Without plant, adult females did not respond to the blend of volatiles associated to conspecifics. However, when plants were considered, Cleopatra mandarin was always preferred to sour orange, irrespective of the infestation status. Moreover, when comparing the same genotype, clean versus infested plants, infested sour orange became repellent, whereas infested 
Cleopatra mandarin became attractive, which correlates the level of direct response with the infestation observed in both genotypes (Figure 1 Suppl.), and confirms our previous observations (Agut et al. 2015). Remarkably, Cleopatra mandarin plants induced by sour orange HIPVs became repellent as well. This result correlates not only with the enhanced expression of SA and JA markers in induced Cleopatra (Figure 1 and 2 Suppl.) but also with a specific volatile profile. From the eight volatiles reported in Table 1, the production of the GLV 2-ethyl-1-hexanol increased in induced Cleopatra, whereas that of two aromatic derivatives and two additional GLVs decreased. These results confirm that Cleopatra mandarin is sensitive to the VOCs-induced direct resistance producing an antixenotic response, which is likely based on the production of a specific blend of volatiles.

The preferences of the three phytoseiids when exposed to the odors of T. urticae, plants, and the combination of these two are shown in Figures 2, 3 and 4. Contrary to what was observed for $T$. urticae, the three predators always preferred the odor of its prey, $T$. urticae, to clean air. This clearly suggests that these predators can effectively smell the herbivore. The characterization of T. urticae volatile profile allowed the identification of twelve compounds that were consistently detected regardless of the mite rearing substrate (Table 2). Seven of them were confirmed with commercial standards and include six GLVs: three simple isoprenoid alcohols, two short-chain aldehydes, and hexanoic acid. The last confirmed volatile in the blend is the HIPV MeSA. Four additional volatiles were tentatively identified as the structurally related lilac ketone and lilac aldehyde isomers. In the experiments where both clean genotypes (no previous mite infestation) were contrasted, all three predators preferred sour orange independently of their degree of specialization (Figures 2 to 4 ). This behavior changed when the phytoseiids had to choose between $T$. urticae-infested plants. The generalist $E$. stipulatus, same as its prey, preferred Cleopatra mandarin whereas the other two phytoseiids showed no preference for any of them. When comparing the same plant genotype, either infested or not, predators always preferred infested plants. Despite these interesting observations, in the experiments where we studied the VOCs-induced indirect defense, we observed that both E. stipulatus and $N$. californicus preferred Cleopatra mandarin-induced plants while $P$. persimilis remained neutral. These diverging results may be related predator diet specialization. 


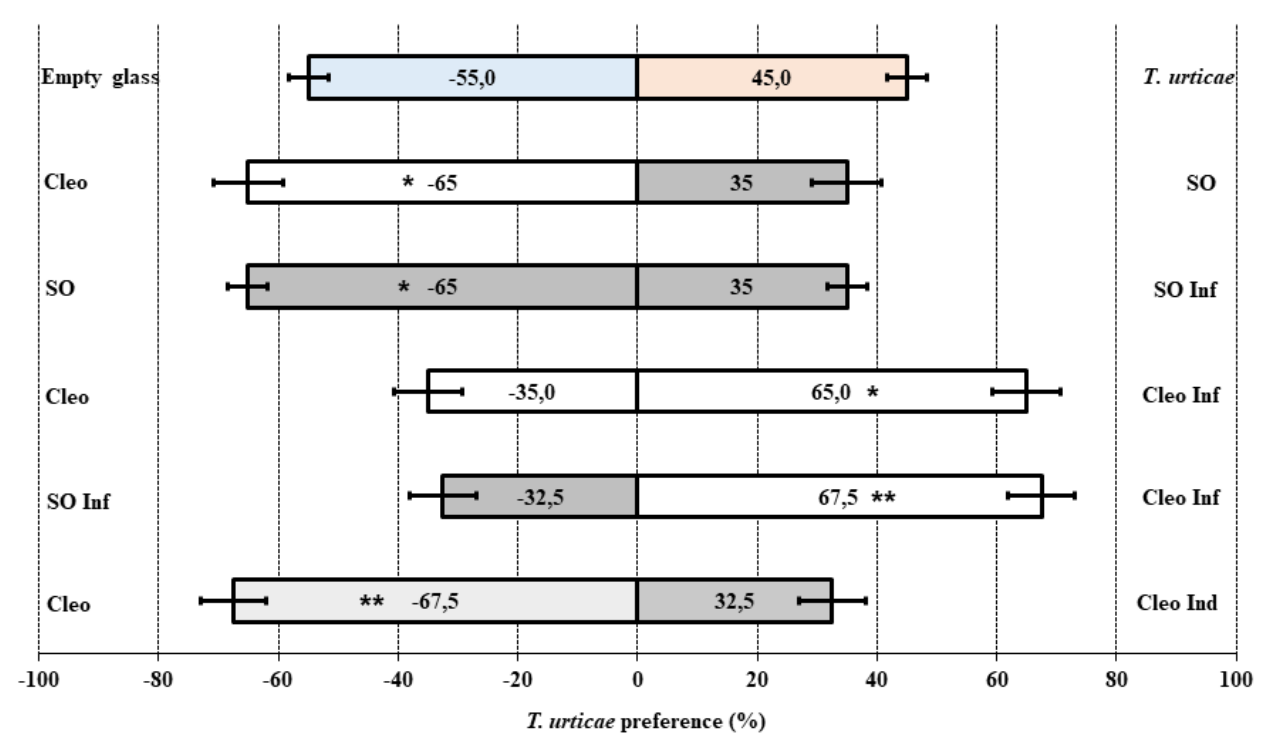

Figure 1. Olfactory response of T. urticae to conspecific mites either with or without plant substrate. Six different combinations, in which $T$. urticae had to choose between two odor sources, were tested. A minimum of 40 adult females per choice combination was tested. These females were subjected to a starvation period of $24 \mathrm{~h}$ prior to the onset of the assay. From top to bottom these combinations were: empty glass versus conspecifics, Cleopatra mandarin untreated plants $(\mathrm{Cleo})$ vs sour orange untreated plants (SO), SO vs SO-infested plants (SO Inf), Cleo vs Cleo-infested plants (Cleo Inf), SO Inf vs Cleo Inf, and Cleo vs Cleo-induced plants (Cleo ind). Infested plants had been exposed to 25 adult females for $48 \mathrm{~h}$ before the onset of the assay. Induced plants had been exposed to sour orange infested plants for 72 hours. Asterisks indicate significant differences from a 1:1 distribution between treatments (chi-square test: $* P<0.10, * * P<0.05$ ). 


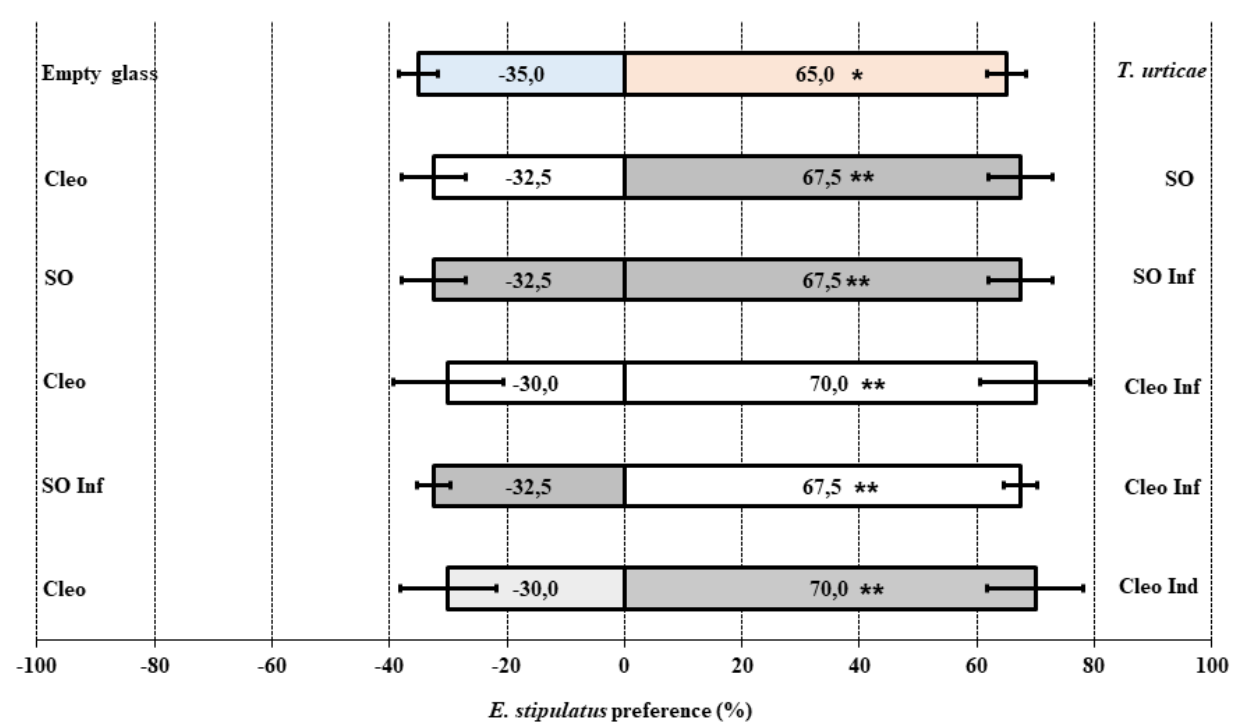

Figure 2. Olfactory response of E. stipulatus to T. urticae either with or without plant substrate. Six different combinations, in which E. stipulatus had to choose between two odor sources, were tested. A minimum of 40 adult females per choice combination was tested. These females were subjected to a starvation period of $24 \mathrm{~h}$ prior to the onset of the assay. From top to bottom these combinations were: empty glass versus conspecifics, Cleopatra mandarin untreated plants (Cleo) vs sour orange untreated plants (SO), SO vs SO-infested plants (SO Inf), Cleo vs Cleo-infested plants (Cleo Inf), SO Inf vs Cleo Inf, and Cleo vs Cleo-induced plants (Cleo ind). Infested plants had been exposed to 25 adult females for $48 \mathrm{~h}$ before the onset of the assay. Induced plants had been exposed to sour orange infested plants for 72 hours. Asterisks indicate significant differences from a 1:1 distribution between treatments (chi-square test: $* P<0.10, * * P<0.05$ ). 


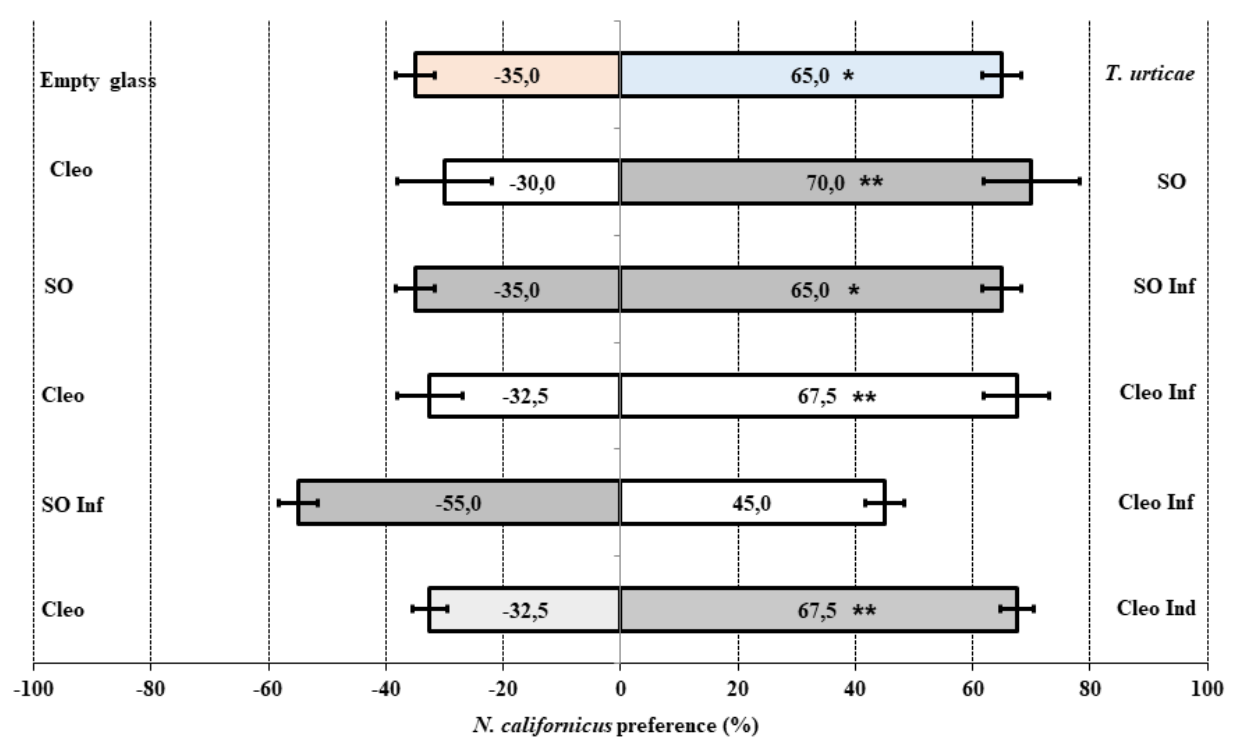

Figure 3. Olfactory response of $N$. californicus to $T$. urticae either with or without plant substrate. Six different combinations, in which $N$. californicus had to choose between two odor sources, were tested. A minimum of 40 adult females per choice combination was tested. These females were subjected to a starvation period of $24 \mathrm{~h}$ prior to the onset of the assay. From top to bottom these combinations were: empty glass versus conspecifics, Cleopatra mandarin untreated plants (Cleo) vs sour orange untreated plants (SO), SO vs SO-infested plants (SO Inf), Cleo vs Cleo-infested plants (Cleo Inf), SO Inf vs Cleo Inf, and Cleo vs Cleo-induced plants (Cleo ind). Infested plants had been exposed to 25 adult females for $48 \mathrm{~h}$ before the onset of the assay. Induced plants had been exposed to sour orange infested plants for 72 hours. Asterisks indicate significant differences from a 1:1 distribution between treatments (chi-square test: $* P<0.10, * * P<0.05$ ). 


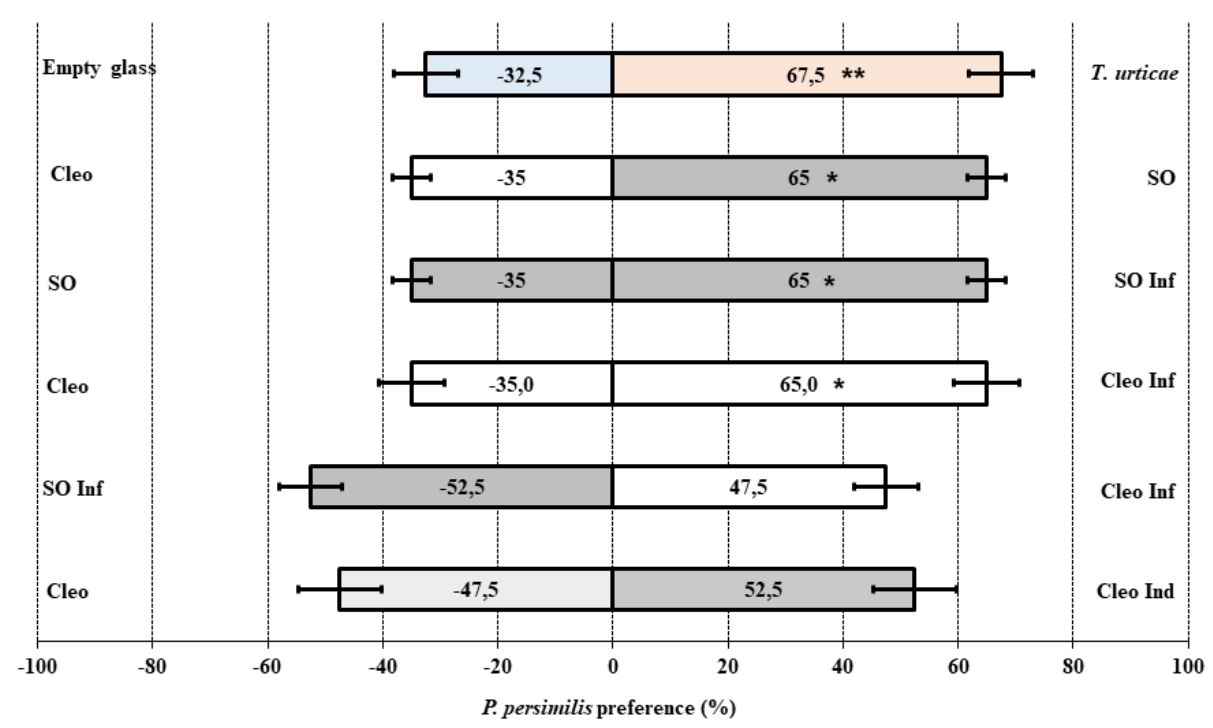

Figure 4. Olfactory response of $P$. persimilis to $T$. urticae either with or without plant substrate. Six different combinations, in which $P$. persimilis had to choose between two odor sources, were tested. A minimum of 40 adult females per choice combination was tested. These females were subjected to a starvation period of $24 \mathrm{~h}$ prior to the onset of the assay. From top to bottom these combinations were: empty glass versus conspecifics, Cleopatra mandarin untreated plants (Cleo) vs sour orange untreated plants (SO), SO vs SO-infested plants (SO Inf), Cleo vs Cleo-infested plants (Cleo Inf), SO Inf vs Cleo Inf, and Cleo vs Cleo-induced plants (Cleo Ind). Infested plants had been exposed to 25 adult females for $48 \mathrm{~h}$ before the onset of the assay. Induced plants had been exposed to sour orange infested plants for 72 hours. Asterisks indicate significant differences from a 1:1 distribution between treatments (chi-square test: $* P<0.10, * * P<0.05$ ). 
Table 1. Tentative identification ${ }^{1}$ of the compounds detected in the headspace of Cleopatra mandarin (Cleo) plants without treatment (Cleo control) or induced by the HIPVs from T. urticae infested sour orange plants (Cleo induced) (mean TOF-MSderived peak areas \pm standard error). Different letters represent significant differences between treatments (analysis of variance, ANOVA, $P<0.05$ ).

\begin{tabular}{lcc}
\hline \multicolumn{1}{c}{ Volatile Compounds } & Cleo control & Cleo induced \\
\hline (1-methylethyl)-Benzene & $8,413.0 \pm 455.9 \mathrm{~b}$ & $15,407.5 \pm 1,485.6 \mathrm{a}$ \\
1-ethyl-2-methyl-Benzene & $30,487.5 \pm 6,152.8 \mathrm{~b}$ & $43,507.5 \pm 3,093.2 \mathrm{a}$ \\
2-ethyl-1-Hexanol & $15,468.7 \pm 3,909.6 \mathrm{~b}$ & $50,200.3 \pm 9,780.5 \mathrm{a}$ \\
3-ethyl-3-methyl-Pentane & $88,573.0 \pm 8,009.3 \mathrm{a}$ & $44,584.7 \pm 870.6 \mathrm{~b}$ \\
2-butoxyethyl Acetate & $20,543.8 \pm 7,199.3 \mathrm{~b}$ & $38,083.7 \pm 3,746.1 \mathrm{a}$ \\
3,5-bis(1,1-dimethylethyl)-4- & $2,550.8 \pm 289.9 \mathrm{a}$ & $1,717.7 \pm 513.9 \mathrm{a}$ \\
hydroxy-methyl ester & & \\
Benzenepropanoic acid & & \\
4-hydroxy-4-methyl-2-Pentanone, & $28,166.5 \pm 4,526.2 \mathrm{a}$ & $24,584.8 \pm 1,477.6 \mathrm{a}$ \\
1R- $\alpha$-Pinene & $60,245.0 \pm 21,100.1 \mathrm{a}$ & $47,417.2 \pm 6,888.6 \mathrm{a}$
\end{tabular}

${ }^{1}$ Tentative identification of the compounds with spectra and high probability matches $(>80 \%)$ according to NIST mass spectral database (Wallis et al., 2008). 
Table 2. Compounds detected in volatile collections of $T$. urticae (relative mean \pm standard error ${ }^{1}$ percentage considering the total chromatogram area of the detected compounds) reared on either lemon fruits or clementine mandarin leaves.

\begin{tabular}{|c|c|c|c|}
\hline \multirow[b]{2}{*}{ Compound } & \multirow[b]{2}{*}{ id. $^{4}$} & \multicolumn{2}{|c|}{ Rearing substrate } \\
\hline & & $\begin{array}{l}\text { Lemon } \\
\text { fruits }\end{array}$ & $\begin{array}{c}\text { Clementine } \\
\text { leaves }\end{array}$ \\
\hline 2-methyl-3-buten-2-ol & $\mathrm{C}$ & $18.34 \pm 5.05$ & $0.51 \pm 0.37$ \\
\hline 3-methyl-3-buten-1-ol & $\mathrm{C}$ & $6.44 \pm 2.00$ & $6.31 \pm 4.06$ \\
\hline 3-methyl-2-buten-1-ol & $\mathrm{C}$ & $18.08 \pm 9.43$ & $2.22 \pm 1.00$ \\
\hline Hexanal & $\mathrm{C}$ & $3.07 \pm 1.13$ & $10.21 \pm 8.92$ \\
\hline Hexanoic acid & $\mathrm{C}$ & $10.73 \pm 4.41$ & $50.91 \pm 20.81$ \\
\hline 5-ethenyldihydro-5-methyl-2(3H)-furanone ${ }^{2}$ & $\mathrm{~T}$ & $3.07 \pm 1.17$ & $5.29 \pm 2.33$ \\
\hline Nonanal & $\mathrm{C}$ & $28.48 \pm 10.04$ & $15.27 \pm 6.48$ \\
\hline $\begin{array}{l}\text { 5-ethenyltetrahydro- } \alpha, 5 \text {-dimethyl-2- } \\
\text { Furanacetaldehyde }{ }^{3} \text { isomer }\end{array}$ & $\mathrm{T}$ & $4.33 \pm 2.54$ & $2.28 \pm 0.48$ \\
\hline Lilac aldehyde isomer & $\mathrm{T}$ & $7.44 \pm 4.11$ & $3.23 \pm 0.87$ \\
\hline Lilac aldehyde isomer & $\mathrm{T}$ & $2.39 \pm 1.39$ & $0.73 \pm 0.26$ \\
\hline Methyl salicylate & $\mathrm{C}$ & $5.23 \pm 3.26$ & $3.20 \pm 2.62$ \\
\hline
\end{tabular}

${ }^{1}$ Means of six replicates for volatile samplings of individuals of the stock colony maintained on lemons and three replicates for samplings of individuals from a colony maintained on clementine mandarin leaves

2 lilac lactone

${ }^{3}$ lilac aldehyde

${ }^{4}$ Identification of the compound: C, confirmed with commercial standard; T, tentative with spectra and high probability matches $(>80 \%)$ according to NIST mass spectral database (Wallis et al., 2008).

\section{DISCUSSION}

\section{Predators are not always attracted to less defended plants}

Sour orange plants display higher constitutive and faster inducible direct defense against T. urticae compared with Cleopatra mandarins, which eventually results in the latter supporting higher T. urticae densities and increased plant damage (Bruessow et al. 2010; Agut et al. 2014, 2015). Therefore, according to our initial hypothesis, infested Cleopatra mandarins were expected to be more attractive for phytoseiids than infested and welldefended sour orange plants. However, in our experimental conditions only the omnivorous predator E. stipulatus, same as the herbivore, preferred Cleopatra mandarin when the two infested genotypes were simultaneously offered (Figures 1 and 2). The other two predators showed no preference for these infested genotypes (Figures 3 and 4). Following the same rationale, induced Cleopatra mandarin plants, which exhibit 
enhanced expression of LOX2 and PR5 genes (Figures 1B and 2B Suppl.), should not have been chosen by predators when simultaneously offered with clean Cleopatra mandarin plants. Indeed, this is what the herbivore did. However, both E. stipulatus and $N$. californicus preferred the better-protected and void-of-prey induced plants, whereas Tetranychus spp.-specialist $P$. persimilis did not show any preference. Consequently, these results provide evidence that predator responses depend on plant genotype and diet specialization. Interestingly, predators are not always attracted to the less defended plants. For omnivores, plant defense induction could be a general clue of $T$. urticae presence in the area.

\section{The well-known negative crosstalk between JA- and SA- defense pathways may be missing in citrus}

Although some trade-offs between direct and indirect defenses have been suggested in specific plant-arthropod interactions (Koricheva et al. 2004), there are also reports in which both sorts of defense function synergistically (Rasmann et al. 2011; Pellissier et al. 2016). This could be the case for citrus as well, as evidenced by our observations in sour orange and induced Cleopatra mandarin plants (Figures 1B and 2B Suppl.). Indeed, sour orange appears to be a jack-of-all-trades, as it seems to have maximized different types of defense against this mite. A clear observation in the absence of infestation is that all predators are more attracted to sour orange, contrary to what was observed for the herbivore. Furthermore, the volatile profile of infested sour orange and induced Cleopatra mandarin changed relative to clean plants. Remarkably, the VOC profiles described in infested sour orange (Agut et al. 2015) and those found in induced Cleopatra mandarin are different and just share the monoterpene pinene. It is very likely that these defense responses are responsible for the repellence of $T$. urticae as well as the attractiveness of phytoseiids. Therefore, the three volatile blends identified so far (those corresponding to infested sour orange, induced Cleopatra mandarin, and T. urticae) are triggering similar behavioral responses in the four mite species studied: attraction of natural enemies but not of the herbivore. These blends deserve further studies, as they may provide new tools to manage these mites in crops.

Plant feeding by spider mites can activate both JA- and SA-related signaling pathways (Kant et al. 2004; Kawazu et al. 2012). However, the decreased performance of these mites (i.e., direct defense) has been associated with the induction of JA-related defenses and the accumulation of additional secondary metabolites such as glucosinolates (Kant et al. 2008; Agut et al. 2014, 2016; Zhurov et al. 2014). Therefore, the simultaneous 
upregulation of both defensive pathways in infested sour orange (Figures 1A and 2A Suppl.; Agut et al. 2014) and in induced Cleopatra mandarin (Figures 1B and 2B Suppl.) indicates that the well-known negative crosstalk between JA- and SA- defense pathways (i.e., the antagonistic interaction between the SA- and the JA-response pathways) (Pieterse et al. 2009; Robert-Seilaniantz et al. 2011) may be missing in citrus.

\section{Tetranychus urticae-associated volatiles include MeSA}

Interestingly, our results have shown that T. urticae associated odors include MeSA (Table 2), a volatile that had been previously identified in Cleopatra mandarin and sour orange HIPVs (Agut et al. 2015). However, we suspect that the amount of MeSA produced by the mite is orders of magnitude below what plants can produce, as we have been unable to detect this compound in infested lemons using the method described above for induced Cleopatra mandarin HIPVs. MeSA had been also found in the blend of volatiles produced by $T$. urticae female teliochrysalis and adult males (both stages were likely present in the mixed pool of mites used to characterize T. urticae associated volatiles) together with three additional volatiles, including methyl cis-dihydrojasmonate (Oku et al. 2015). In their study, this blend was shown to mediate male discrimination between male-guarded and solitary female teliochrysalis. Although different butterfly species of the genus Pieris Schrank (Lepidoptera: Pieridae) can use the amino acid phenylalanine as a precursor to MeSA (Andersson et al. 2000, 2003), T. urticae most probably obtains this volatile from its host plants (Oku et al. 2015). Because SA has been widely recognized as a key factor for predator recruitment by infested plants (i.e., indirect defense) (Rodríguez-Saona et al. 2011; Kaplan 2012; Mallinger et al. 2011; Rowen et al. 2017; Salamanca et al. 2017), the question of why a plant volatile exploited by natural enemies as a kairomone is not immobilized/degraded by its potential prey, deserves further investigations.

\section{Blends rather than single compounds matter}

Importantly, it is often the whole blend rather than single volatiles what predatory mites exploit to communicate (Clavijo-McCormick et al. 2012). Indeed, in their study Oku et al. (2015) could not attribute the behavioral differences observed in male T. urticae to a single compound but to the whole blend. Moreover, van Wijk et al. (2008, 2011), showed that although MeSA alone, which was produced by T. urticae-injured lima bean plants, was attractive to $P$. persimilis, attraction increased when MeSA was part of the natural HIPV blend produced by the plant. Interestingly, one of the volatiles in that blend, the 
GLV (Z)-3-hexenyl acetate, was repellent to $P$. persimilis when tested alone. Likewise, in our case, attraction to the three phytoseiids tested could be attributed to the blend in Table 2 rather than to a single volatile. Most of these compounds have been reported as aggregation pheromones in several bark beetles (Bakke et al. 1977; Stoakley et al. 1978; Bowers et al. 1991). Lilac related compounds have been described as volatile constituents of plant essential oils (Jerković et al. 2017; Peron et al. 2017). Moreover, lilac aldehyde stereoisomers have been identified in the flower scent of many plant species, with an important role for the attraction of pollinators (Dötterl and Jürgens 2005; Dötterl et al. 2006). Although the role of T. urticae associated volatiles needs further investigations, their origin, same as MeSA, is likely the host plant (Castro-Vázquez et al. 2009), from where they may have been acquired either directly or as precursors (Reddy and Guerrero 2004).

\section{Diet specialization may partly explain phytoseiid choices}

As pointed out earlier, the SA-dependent signaling pathway is considered key for indirect defense. Actually, MeSA has been shown to attract phytoseiid mites (de Boer and Dicke 2004; van Wijk et al. 2008, 2011; Shimoda 2010). Therefore, plants with relatively enhanced activation of the SA signaling pathway were expected to be selected by phytoseiids in our two choice-tests. However, this was not always the case. For most of these exceptions, an over-ruling of prey-related odors, which interestingly include MeSA (Table 2), can explain the results. This is the case of $N$. californicus and P. persimilis, which showed no preference when offered the two infested genotypes (when a preference for infested Cleopatra mandarin was anticipated as MeSA levels are higher in this genotype, Agut et al. 2015). Nevertheless, this prey over-ruling hypothesis does not explain the preferences of E. stipulatus and N. californicus for induced Cleopatra mandarin over clean Cleopatra plants (where no preference was expected as MeSA was not differentially produced in these genotypes; Table 1). These differences among predators may be partly due to their different diet specializations (McMurtry and Croft 1997; McMurtry et al. 2013), which may affect the interpretation of the meaning of the different volatile blends.

The high polyphagy of T. urticae (Migeon and Dorkeld 2006-2017) results in the induction of quantitatively and qualitatively different HIPVs in different host plants (Van den Boom et al. 2004) and this might hamper prey location by its natural enemies. $P$. persimilis can locate their prey from a distance using volatiles, including MeSA, emitted by plants infested with spider mites (Sabelis and van de Baan 1983; Sabelis et al. 1984; 
Dicke et al. 1990). However, this phytoseiid selected volatiles from prey-infested leaves, T. urticae, rather than leaves infested with a non-prey close relative, Panonychus ulmi (Koch) (Acari: Tetranychidae) (Sabelis and van de Baan 1983). For specialist predators (i.e., P. persimilis), the density of its main prey on the infested plant has to be enough as a reward as this is their only suitable food for complete development and successful reproduction. Therefore, it is not surprising that in our experiments $P$. persimilis responded mainly to the blend of T. urticae-associated volatiles (Figure 4). Although it detected and reacted to the upregulation of SA-signaling PR5 gene in clean sour orange when offered together with clean Cleopatra mandarin, the lower levels in induced Cleopatra mandarin (Figure 2B Suppl.) did not trigger the same behavior when the predator had to choose between induced and clean Cleopatra mandarin plants. Indeed, this predator is known to respond to MeSA, which was induced in both sour orange and Cleopatra mandarin by T. urticae (Agut et al. 2015), in a dose-dependent manner (de Boer and Dicke 2004). However, for extreme omnivorous predators, including zoophytophagous species, which can obtain their food from different prey species and even from the host plant, both prey-specific chemical cues and HIPVs may be equally important to select patches with enough prey diversity and abundance but also with minimal plant direct defense. E. stipulatus is the only predator from the three species included in this study that most probably belongs to the group of phytoseiids that may complement their nutrition requirements by feeding on leaf epidermal cells (Adar et al. 2012; McMurtry et al. 2013). Therefore, E. stipulatus may benefit from choosing the plant genotype showing the weakest defense when infested by T. urticae (Agut et al. 2014). By preferring Cleopatra mandarin to sour orange when both genotypes were infested (Figure 2), E. stipulatus also selects the host likely offering higher densities of the prey and this would eventually benefit the plant as well, as this omnivorous predator may choose to feed preferentially on the prey and not on the plant. As MeSA was not differentially produced in the blend of volatiles produced by Cleopatra mandarin upon induction by sour orange HIPVs (Table 1), other volatiles must have a more important role in governing E. stipulatus choices and this should be partly true for $N$. californicus as it exhibited a behavior in between this generalist and the specialist $P$. persimilis.

\section{Concluding remarks}

To sum up, our results provide evidence that the response of the four mite species included in this study is plant genotype dependent and is modulated by their feeding habits, as well as by the presence of the herbivore on the plant. Some of these behavioral 
responses in T. urticae had already been described by our group (Agut el al. 2015). Interestingly, the discrimination by $T$. urticae between Cleopatra mandarin plants either clean or induced with HIPVs from T. urticae-infested sour orange, and the fact that this mite did not show any preference when exposed to volatiles emitted by conspecifics, confirms that this behavior is triggered by plant HIPVs only. Further research focused on the three volatile blends that have been identified in this study as attractive for T. urticae natural enemies but not for the herbivore could provide new more sustainable tools with clear applications in crop protection (i.e., use of volatile dispensers for predator recruitment and plant defense enhancement). Furthermore, the accumulation of MeSA in T. urticae, which, on the one hand, may have a direct impact on plant defense (i.e., priming) and, on the other, on recruiting natural enemies, should be also further studied.

\section{Acknowledgments}

The research leading to these results was partially funded by the Spanish Ministry of Economy and Competitiveness (AGL2014-55616-C3; AGL2015-64990-2R). The authors thank M. Piquer (UJI) for technical assistance. MC received a pre-doctoral fellowship from the Spanish Ministry of Economy and Competitiveness (BES-2015074570) and MP was the recipient of a research fellowship from INIA, Spain (subprogram DOC INIA-CCAA).

Author Contributions Statement: JJ, MP, VF and VN designed the assays, which were performed by JC, MC, and SV. All authors analyzed the results and contributed to the writing of the manuscript.

\section{Compliance with Ethical Standards}

Funding: this study was partially funded by the Spanish Ministry of Economy and Competitiveness, MINECO, (grants AGL2014-55616-C3, AGL2015-64990-2R, BES2015-074570 and DOC-INIA-CCAA).

Conflict of Interest: no conflict of interest exists.

Ethical approval: this article does not contain any studies with human participants performed by any of the authors. 


\section{References}

Abad-Moyano, R., Pina, T., Ferragut, F., and Urbaneja, A. (2009). Comparative lifehistory traits of three phytoseiid mites associated with Tetranychus urticae (Acari: Tetranychidae) colonies in clementine orchards in eastern Spain: implications for biological control. Exp. Appl. Acarol. 47:121-132.

Adar, E., Inbar, M., Gal, S., Doron, N., Zhang, Z. Q., and Palevsky, E. (2012). Plantfeeding and non-plant feeding phytoseiids: differences in behavior and cheliceral morphology. Exp. Appl. Acarol. 58:341-357.

Aguilar-Fenollosa, E., Ibáñez-Gual, M. V., Pascual-Ruiz, S., Hurtado, M., and Jacas, J. A. (2011). Effect of ground-cover management on spider mites and their phytoseiid natural enemies in clementine mandarin orchards (I): bottom-up regulation mechanisms. Biol. Control. 59:158-170.

Agut, B., Gamir, J., Jacas, J. A., Hurtado, M., and Flors, V. (2014). Different metabolic and genetic responses in citrus may explain relative susceptibility to Tetranychus urticae. Pest Manag. Sci. 70:1728-1741.

Agut, B., Gamir, J., Jaques, J. A., and Flors, V. (2015). Tetranychus urticae-triggered responses promote genotype-dependent conspecific repellence or attractiveness in citrus. New Phytol. 207:790-804.

Agut, B., Gamir, J., Jaques, J. A., and Flors, V. (2016). Systemic resistance in citrus to Tetranychus urticae induced by conspecifics is transmitted by grafting and mediated by mobile amino acids. J. Exp. Bot. 67:5711-5723.

Alfaro, C., Vacas, S., Zarzo, M., Navarro-Llopis, V., and Primo, J. (2011). Solid phase microextraction of volatile emissions of Ceratitis capitata (Wiedemann) (Diptera: Tephritidae): influence of fly sex, age, and mating status. J. Agric. Food Chem. 59:298306.

Aljbory, Z., and Chen, M. S. (2018). Indirect plant defense against insect herbivores: a review. Insect Sci. 25:2-23.

Andersson, J., Borg-Karlson, A. K., and Wiklund, C. (2000). Sexual cooperation and conflict in butterflies: A male-transferred anti-aphrodisiac reduces harassment of recently mated females. Proc. R. Soc. London B 267:1271.

Andersson, J., Borg-Karlson, A. K., and Wiklund, C. (2003). Antiaphrodisiacs in pierid butterflies: a theme with variation!. Journal of chemical ecology 29:1489-1499.

Bakke, A., Froyen, P., and Skattebol, L. 1977. Field response to a new pheromonal compound isolated from Ips typographus. Naturwissenschaften 64:98.

Bañuls, J., Serna, M. D., Legaz, F., Talon, M., and Primo-Millo, E. (1997). Growth and gas exchange parameters of Citrus plants stressed with different salts. J. Plant Physiol. 150:194-199.

Bowers, W. W., Gries, G., Borden, J. H., and Pierce, H. D. (1991). 3-Methyl-3-buten-1ol: An aggregation pheromone of the four-eyed spruce bark beetle, Polygraphus rufipennis (Kirby) (Coleoptera: Scolytidae). J. Chem. Ecol. 17:1989-2002. 
Bruessow, F., Asins, M.J., Jacas, J.A., and Urbaneja, A. (2010). Replacement of CTV susceptible sour orange rootstock by CTV-tolerant ones may have triggered outbreaks of Tetranychus urticae in Spanish citrus. Agr. Ecosyst. Environ. 137:93-98.

Bruin, J., Dicke, M., and Sabelis, M. W. (1992). Plants are better protected against spidermites after exposure to volatiles from infested conspecifics. Experientia 48:525-529.

Bruinsma, M., Van Broekhoven, S., Poelman, E. H., Posthumus, M. A., Müller, M. J., Van Loon, J. J., and Dicke, M. (2010). Inhibition of lipoxygenase affects induction of both direct and indirect plant defences against herbivorous insects. Oecologia 162:393404.

Cambra, M., Gorris, M. T., Marroquin, C., Román, M. P., Olmos, A., Martınez, M. C., Hermoso de Mendoza, A., López, A., and Navarro, L. (2000). Incidence and epidemiology of Citrus tristeza virus in the Valencian Community of Spain. Virus Res. 71:85-95.

Castro-Vázquez, L., Díaz-maroto, M.C., González-Viñas, M.A., and Pérez-Coello, M. (2009). Differentiation of monofloral citrus, rosemary, eucalyptus, lavender, thyme and heather honeys based on volatile composition and sensory descriptive analysis. Food Chem. 112:1022-1030.

Clavijo McCormick, A., Unsicker, S.B., and Gershenzon, J. (2012). The specificity of herbivore-induced plant volatiles in attracting herbivore enemies. Trends Plant Sci. 17:303-310.

Cortés, L. E., Weldegergis, B. T., Boccalandro, H. E., Dicke, M., and Ballaré, C. L. (2016). Trading direct for indirect defense? Phytochrome B inactivation in tomato attenuates direct anti-herbivore defenses whilst enhancing volatile-mediated attraction of predators. New Phytol. 212:1057-1071.

De Boer, J. G., and Dicke, M. (2004). The role of methyl salicylate in prey searching behavior of the predatory mite Phytoseiulus persimilis. J. Chem. Ecol. 30:255-271.

Dicke, M., Sabelis, M. W., Takabayashi, J., Bruin, J., and Posthumus, M. A. (1990). Plant strategies of manipulating predatorprey interactions through allelochemicals: prospects for application in pest control. J. Chem. Ecol. 16:3091-3118.

Dötterl, S., and Jürgens, A. (2005). Spatial fragrance patterns in flowers of Silene latifolia: lilac compounds as olfactory nectar guides? Plant Syst. Evol. 255:99-109.

Dötterl, S., Burkhardt, D., Weißbecker, B., Jürgens, A., Schütz, S., and Mosandl, A. (2006). Linalool and lilac aldehyde/alcohol in flower scents: Electrophysiological detection of lilac aldehyde stereoisomers by a moth. J. Chromatogr. A. 1113:231-238.

Gómez-Martínez, M. A., Jaques, J. A., Ibáñez-Gual, M. V., and Pina, T. (2018). When the ground cover brings guests: is Anaphothrips obscurus a friend or a foe for the biological control of Tetranychus urticae in clementines?. J. Pest Sci. 91:613-623.

Hoy, M. A. (2011) Agricultural Acarology: Introduction to Integrated Mite Management. CRC Press (Taylor and Francis Group), Boca Raton, Florida, USA. 
Huffaker, C., Van de Vrie, M., and McMurtry, J. (1970). Ecology of tetranychid mites and their natural enemies: A review: II. Tetranychid populations and their possible control by predators: An evaluation. Hilgardia. 40:391-458.

Jacas, J. A., and Urbaneja, A. (2010). Biological control in citrus in Spain: from classical to conservation biological control. In Integrated management of arthropod pests and insect borne diseases (pp. 61-72). Springer, Dordrecht.

Jerković, I., Molnar, M., Vidović, S., Vladić, J., and Jokić, S. (2017). Supercritical CO2 Extraction of Lavandula angustifolia Mill. Flowers: Optimisation of Oxygenated Monoterpenes, Coumarin and Herniarin Content. Phytochem. Analysis 28:558-566.

Kant, M. R., Ament, K., Sabelis, M. W., Haring, M. A. and Schuurink, R. C. (2004). Differential timing of spider mite-induced direct and indirect defenses in tomato plants. Plant Physiol. 135:483-495.

Kant, M. R., Sabelis, M. W., Haring, M. A. and Schuurink, R. C. (2008). Intraspecific variation in a generalist herbivore accounts for differential induction and impact of host plant defences. Proceedings of the Royal Society of London B: Biol. Sci. 275:443-452.

Kaplan, I. (2012). Attracting carnivorous arthropods with plant volatiles: the future of biocontrol or playing with fire? Biol. Control 60:77-89.

Kawazu, K., Mochizuki, A., Sato, Y., Sugeno, W., Murata, M., Seo, S., and Mitsuhara, I. (2012). Different expression profiles of jasmonic acid and salicylic acid inducible genes in the tomato plant against herbivores with various feeding modes. Arthropod-Plant Inte. 6:221-230.

Kiefer, E., Heller, W., and Ernst, D. (2000). A simple and efficient protocol for isolation of functional RNA from plant tissues rich in secondary metabolites. Plant Mol. Biol. Rep. 18:33-39.

Koricheva, J., Nykänen, H., and Gianoli, E. (2004). Meta-analysis of trade-offs among plant antiherbivore defenses: are plants jacks-of-all-trades, masters of all? Am. Nat. 163:E64-E75.

Mallinger, R. E., Hogg, D. B., and Gratton, C. (2011). Methyl salicylate attracts natural enemies and reduces populations of soybean aphids (Hemiptera: Aphididae) in soybean agroecosystems. J. Econ. Entomol. 104:115-124.

McMurtry, J. A., and Croft, B. A. (1997). Life-styles of phytoseiid mites and their roles in biological control. Annu. Rev. Entomol. 42:291-321.

McMurtry, J. A., Moraes, G. J. D., and Sourassou, N. F. (2013). Revision of the lifestyles of phytoseiid mites (Acari: Phytoseiidae) and implications for biological control strategies. Syst. Appl. Acarol. 18:297-320.

Migeon, A. and Dorkeld, F. (2006-2017) Spider Mites Web: a comprehensive database for the Tetranychidae. http://www.montpellier.inra.fr/CBGP/spmweb (accessed April 13, 2018).

Oku, K., Weldegergis, B.T., Poelman, E.H., De Jong, P.W., and Dicke, M. (2015). Altered volatile profile associated with precopulatory mate guarding attracts spider mite males. J. Chem. Ecol. 41:187-193. 
Pascual-Ruiz, S., Aguilar-Fenollosa, E., Ibáñez-Gual, V., Hurtado-Ruiz, M. A., MartínezFerrer, M. T., and Jacas, J. A. (2014). Economic threshold for Tetranychus urticae (Acari: Tetranychidae) in clementine mandarins Citrus clementina. Exp. Appl. Acarol. 62:337362.

Pellissier, L., Moreira, X., Danner, H., Serrano, M., Salamin, N., Dam, N. M., and Rasmann, S. (2016). The simultaneous inducibility of phytochemicals related to plant direct and indirect defences against herbivores is stronger at low elevation. $J$. Ecol. 104:1116-1125.

Pérez-Sayas, C., Pina, T., Gómez-Martínez, M. A., Camañes, G., Ibáñez-Gual, M. V., Jaques, J. A., and Hurtado, M. A. (2015). Disentangling mite predator-prey relationships by multiplex PCR. Mol. Ecol. Resour. 15:1330-1345.

Peron, G., Baldan, V., Sut, S., Faggian, M., Roccabruna, L., Zanini, D., Manzini, P., Maggi, F.and Dall'Acqua, S. (2017). Phytochemical investigations on Artemisia alba Turra growing in the North-East of Italy. Nat. Prod. Res. 31:1861-1868.

Pieterse, C. M., Leon-Reyes, A., Van der Ent, S., and Van Wees, S. C. (2009). Networking by small-molecule hormones in plant immunity. Nat. Chem. Biol. 5:308.

Rasmann, S., Erwin, A. C., Halitschke, R., and Agrawal, A. A. (2011). Direct and indirect root defences of milkweed (Asclepias syriaca): trophic cascades, trade-offs and novel methods for studying subterranean herbivory. J. Ecol. 99:16-25.

Reddy, G. V., and Guerrero, A. (2004). Interactions of insect pheromones and plant semiochemicals. Trends Plant Sci. 9:253-261.

Robert-Seilaniantz, A., Grant, M., and Jones, J. D. (2011). Hormone crosstalk in plant disease and defense: more than just jasmonate-salicylate antagonism. Annu. Rev. Phytopathol. 49:317-343.

Rodriguez-Saona, C., Kaplan, I., Braasch, J., Chinnasamy, D., and Williams, L. (2011). Field responses of predaceous arthropods to methyl salicylate: a meta-analysis and case study in cranberries. Biol. Control 59:294-303.

Rowen, E., Gutensohn, M., Dudareva, N., and Kaplan, I. (2017). Carnivore Attractant or Plant Elicitor? Multifunctional Roles of Methyl Salicylate Lures in Tomato Defense. $J$. Chem. Ecol. 43:573-585.

Sabelis, M. W., and Baan, H. V. D. (1983). Location of distant spider mite colonies by phytoseiid predators: demonstration of specific kairomones emitted by Tetranychus urticae and Panonychus ulmi. Entomol. Exp. Appl. 33:303-314.

Sabelis, M. W., Vermaat, J. E., and Groeneveld, A. (1984). Arrestment responses of the predatory mite, Phytoseiulus persimilis, to steep odour gradients of a kairomone. Physiol. Entomol. 9:437-446.

Salamanca, J., Souza, B., Lundgren, J. G., and Rodriguez-Saona, C. (2017). From laboratory to field: electro-antennographic and behavioral responsiveness of two insect predators to methyl salicylate. Chemoecology 27:51-63. 
Shimoda, T. (2010). A key volatile infochemical that elicits a strong olfactory response of the predatory mite Neoseiulus californicus, an important natural enemy of the twospotted spider mite Tetranychus urticae. Exp. Appl. Acarol. 50:9-22.

Stoakley, J.T., Bakke, A., Renwick, J.A.A., and Vité, J.P. (1978). The aggregation pheromone system of the larch beetle, lps cembrae Heer. Z. Angew. Entomol. 86:174177.

Van Den Boom, C. E., Van Beek, T. A., Posthumus, M. A., De Groot, A., and Dicke, M. (2004). Qualitative and quantitative variation among volatile profiles induced by Tetranychus urticae feeding on plants from various families. J. Chem. Ecol. 30:69-89.

Van Wijk, M., De Bruijn, P. J. and Sabelis, M. W. (2008). Predatory mite attraction to herbivore-induced plant odors is not a consequence of attraction to individual herbivoreinduced plant volatiles. J. Chem. Ecol. 34:791-803.

Van Wijk, M., De Bruijn, P. J. and Sabelis, M. W. (2011). Complex odor from plants under attack: herbivore's enemies react to the whole, not its parts. PloS One. 6:e21742.

Wallis, C., Eyles, A., Chorbadjian, R., McSpadden-Gardener, B., Hansen, R., Cipollini, D., Herms, D.A., and Bonello, P. (2008). Systemic induction of phloem secondary metabolism and its relationship to resistance to a canker pathogen in Austrian pine. New Phytol. 177:767-778.

Zhurov, V., Navarro, M., Bruinsma, K. A., Arbona, V., Santamaria, M. E., Cazaux, M., ... and Vermeirssen, V. (2014). Reciprocal responses in the interaction between Arabidopsis and the cell-content-feeding chelicerate herbivore spider mite. Plant Physiol. 164:384-399. 


\section{Supplementary material}

Table 1 suppl. Primers used in qRT-PCR reactions.

\begin{tabular}{clll}
\hline Description & \multicolumn{1}{c}{ Accession } & Forward primer $\mathbf{5}^{\prime} \rightarrow \mathbf{3}^{\prime}$ & Reverse primer $\mathbf{5}^{\prime} \rightarrow \mathbf{3}^{\prime}$ \\
\hline LOX2 & Cit.16756.1.S1 & GAACCATATTGCCAC & CGTCATCAATGACT \\
& S_at & TTTCG & TGACCA \\
\multirow{2}{*}{$P R 5$} & BAI63297.1 & CATCAAGCTTCACAG & CCACAACGTACAG \\
& & TGCTTAG & ACTGATGAC \\
GAPDH & \multirow{2}{*}{ Cit.122.1 } & GGAAGGTCAAGATC & CGTCCCTCTGCAAG \\
& & GGAATCAA & ATGACTCT \\
\hline
\end{tabular}



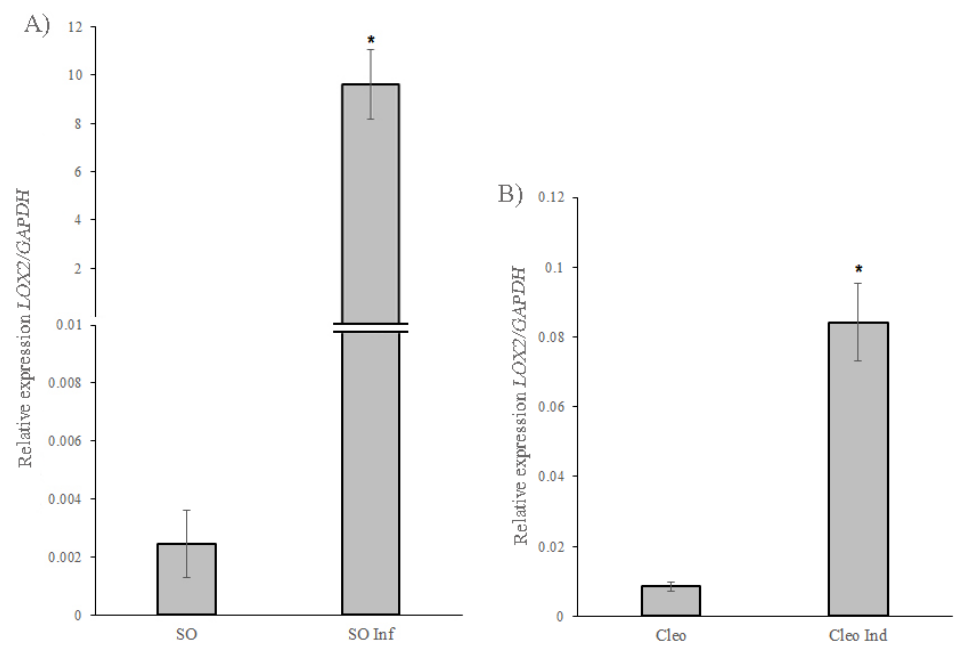

Figure 1 suppl. Induction of defensive pathways in Cleopatra mandarin by exposure to HIPVs produced by neighboring sour orange plants infested with $T$. urticae. Lipoxygenase 2 gene ( $L O X 2$ ) induction following different treatments; A) LOX2 expression in untreated sour orange plants and $72 \mathrm{~h}$ post-infested sour orange plants with T. urticae. B) $L O X 2$ expression in untreated Cleopatra mandarin plants and at $72 \mathrm{~h}$ postexposure to sour orange herbivore-induced plant volatiles (HIPVs). The $L O X 2$ transcript levels were normalized to the expression of the housekeeping gene glyceraldehyde 3phosphate dehydrogenase $(G A P D H)$ measured in the same sample. The data are presented with a representative figure for four independent experiments of the analysis behavior through the olfactometer of the mites studied in the present work, in Cleopatra mandarin induced plants. Significant differences in the relative transcript levels between different treatments were estimated using a $t$-test. The asterisk indicates significant difference to different treatments $(t$-test; $P<0.05)$. 

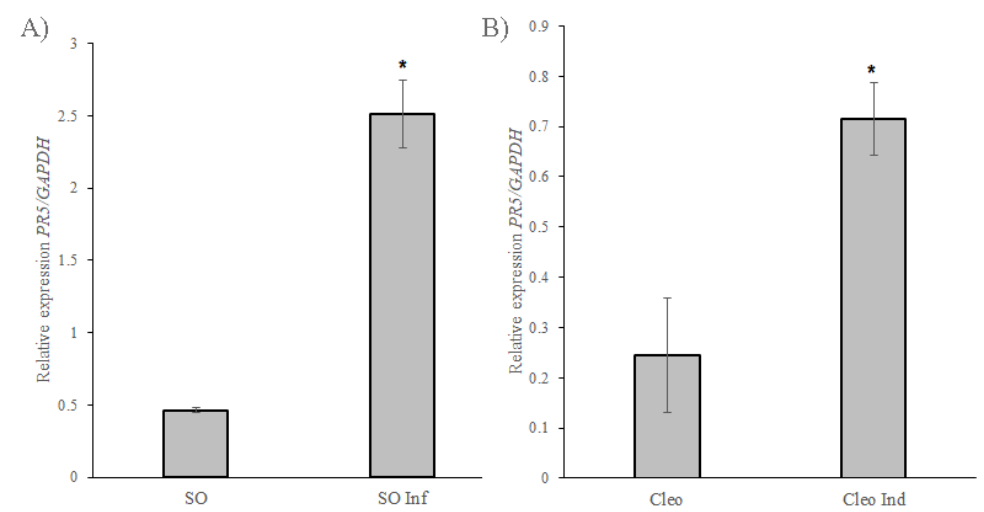

Figure 2 suppl. Induction of defensive pathways in Cleopatra mandarin by exposure to HIPVs produced by neighboring sour orange plants infested with $T$. urticae. Pathogenesis-related protein 5 (PR5) induction following different treatments; A) PR5 expression in untreated sour orange plants and $72 \mathrm{~h}$ post-infested sour orange plants with T. urticae. B) PR5 expression in untreated Cleopatra mandarin plants and at $72 \mathrm{~h}$ postexposure to sour orange herbivore-induced plant volatiles (HIPVs). The PR5 transcript levels were normalized to the the housekeeping gene glyceraldehyde 3-phosphate dehydrogenase $(G A P D H)$ measured in the same sample. The data are presented with a representative figure for the four independent experiments of the analysis behavior through the olfactometer of the mites studied in the present work, in Cleopatra mandarin induced plants. Significant differences in the relative transcript levels between different treatments were estimated using a $t$-test. The asterisk indicates significant difference to different treatments $(t$-test; $P<0.05)$. 